\section{Vorsicht geboten}

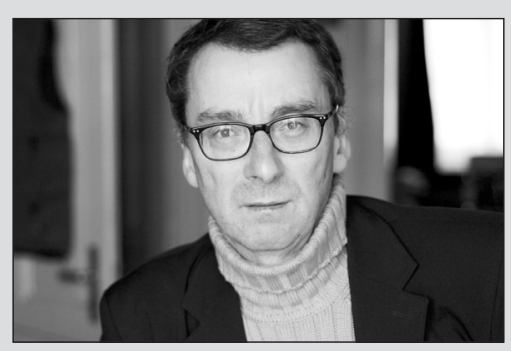

Das Finanzierungsmanagement gewinnt in sozialen Organisationen immer größere Bedeutung. $Z u$ einem klugen Haushalten kann es dabei durchaus gehören zu prüfen, ob wünschenswerte aber schwierig zu finanzierende Investitionen wirklich erforderlich sind, wie

Dr. Berthold Becher in seinen Thesen in diesem Heft erläutert (Seite 13). Der Ausstieg aus einem Leistungsangebot, das Leasing, das Outsourcing oder der Rückzug auf die Betreiberrolle können mögliche Optionen sein.

Insbesondere gemeinnützige Unternehmen der Sozialwirtschaft sind für neue Investitionen wegen der beschränkten Möglichkeiten, eigene Rücklagen zu bilden, auf fremdes Kapital angewiesen. Dennoch gibt es auch für sie Möglichkeiten, die Eigenkapitalquote zu verbessern. Wie durch die Hebung stiller Reserven und die Aufnahme von »Mezzaninkapital « die Liquidität verbessert werden kann, zeigt der Münchner Wirtschaftsprüfer und Steuerberater Dr. Stefan Kusterer in seinem Beitrag in diesem Heft (Seite 19).

Vorsicht geboten ist bei den heute üblichen Investorenmodellen für Sozialimmobilien. Diese können nach Ansicht von Willi Esser, kaufmännischer Vorstand der Johannes Seniorendienste in Bonn, für viele Einrichtungsträger zur Kostenfalle werden. Seine Empfehlungen für einen vernünftigen Pachtvertrag lauten: Laufzeit maximal 20 Jahre, als Basis der Pachtzahlung ein Investitionsfolgesatz gemäß der Vereinbarung mit den Kostenträgern, keine automatischen Pachterhöhungen (Seite 17).

Um Finanzen geht es auch im nächsten Kongress der Sozialwirtschaft* am 26. und 27. April 2007 in Magdeburg. Das Rahmenthema »Europa sozial managen " wird die drei Aspekte Werte, Wettbewerb und Finanzen beleuchten. Veranstalter dieses alle zwei Jahre stattfindenden Branchentreffs sind die Bundesarbeitsgemeinschaft der Freien Wohlfahrtspflege, die Bank für Sozialwirtschaft und die Nomos Verlagsgesellschaft. Die Schirmherrschaft übernommen hat Dr. Ursula von der Leyen, Bundesministerin für Familie, Senioren, Frauen und Jugend. Der Kongress der Sozialwirtschaft ist Teil der offiziellen Veranstaltungen der gegenwärtigen deutschen Ratspräsidentschaft der Europäischen Gemeinschaft.

Gerhard Pfannendörfer - Chefredaktion -

* Detaillierte Informationen gibt es auf der Website der Veranstaltung: http://www.kongress-der-sozialwirtschaft.de.

\section{Praxiswissen für die Sozialwirtschaft}

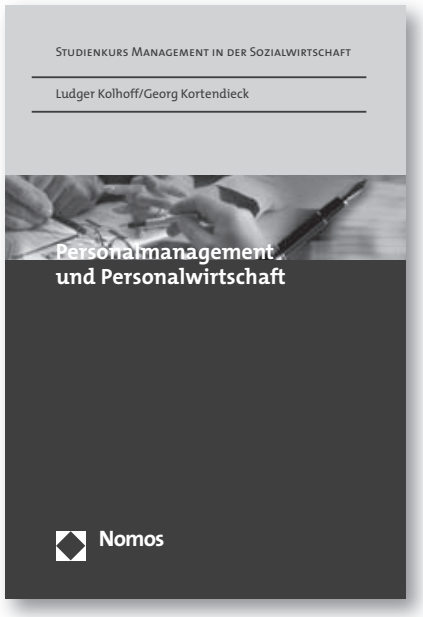

Personalmanagement und Personalwirtschaft Von Prof. Dr. phil. Ludger Kolhoff und Prof. Dr. rer. pol. Georg Kortendieck 2006, 176 S., brosch., 19,80€, ISBN 978-3-8329-1633-6 (Studienkurs Management in der Sozialwirtschaft)

Studierende und Praktiker erhalten in dem Werk einen praxis- wie theoriegeleiteten Überblick über die wichtigsten Bereiche des Personalmanagements und der Personalwirtschaft.

Es werden die grundlegenden theoretischen Hintergründe untersucht und zentrale wie aktuelle Aspekte und Ansichten der Personalführung, Personalplanung, Personalbeschafffung, Personalhonorierung, Personalbeurteilung und auch der Personalentwicklung in der Sozialwirtschaft behandelt.

Bitte bestellen Sie bei Ihrer Buchhandlung oder bei Nomos C07221/2104-37 | 를-43 www.nomos.de | sabine.horn@nomos.de

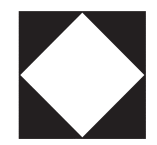

